\title{
The frequency of morphological defects of epididymal sperm in exotic animal species of the family Bovidae kept in the Czech Republic
}

\author{
Jaroslav Šípek, Věra Kopecká, Petra Přinosilová, Jiří Rubeš \\ Central European Institute of Technology-Veterinary Research Institute, \\ Department of Genetics and Reproductive Biotechnologies, Brno, Czech Republic
}

Received December 8, 2020

Accepted August 31, 2021

\begin{abstract}
Epididymal sperm morphology was evaluated by strict criteria using the DeSMA software. A total of 134 animals from the Dvůr Králové ZOO were included in the study. The aim of this study was to determine the prevalence of morphological defects of epididymal sperm in animals of the family Bovidae in species that are not native to the Czech Republic and are bred here only in zoos. Our results showed that the frequency of abnormalities was higher in exotic species of the Bovidae family compared to domestic species. Furthermore, the acquired defects prevailed over developmental abnormalities. Cytoplasmic droplets are a characteristic feature of epididymal sperm. Their average prevalence in the whole Bovidae family is almost $30 \%$. However, distal droplets are not considered to be sperm pathology and, therefore, they are not the most frequent defect. The most common abnormalities are acquired head defects, followed by acquired tail defects, and then by acquired neck defects, mainly represented by proximal cytoplasmic droplets. The lowest prevalence was found for developmental abnormalities, with heads being more often affected than tails. The remaining defects were sporadic.
\end{abstract}

Antelopes, spermatology, DeSMA

Even though the need for establishing genetic reserves for endangered animal species is increasing today, very few authors deal with the characterization of sperm of these species (Cassinello et al. 1998; Sontakke et al. 2009). In addition, the possibilities of obtaining sperm from wildlife species are very limited.

Anumber of methods for obtaining sperm from various animal species have been described. One of the most common semen collection methods in wildlife species is electroejaculation described by many authors (Wildt et al. 1986; Roth et al. 1998; Suwanpugdee et al. 2009). A disadvantage of this technique is that it can cause considerable stress. However, it can be used repeatedly in the animals. Nowadays, the technique of post mortem sperm retrieval allowing collection of sperm from different parts of the epididymis is often used, especially for research purposes. This method can be effectively used in animals after sudden death or after emergency slaughter, and the extracted sperm can then be used for preservation of genetic material or used in further studies. It is well-known that sperm from the tail of the epididymis have an adequate degree of maturity and the ability to fertilize the oocytes (Turner 1995; Foote 2000). A comparison of two different methods of sperm recovery from the epididymis of red deer was made by Martinez-Pastor et al. (2006). Based on the total number of obtained sperm, degree of contamination, and sperm quality indicators, these authors preferred the method of flushing sperm from the epididymis to the method of epididymis slicing. On the other hand, the method of slicing (Songsasen et al. 1998; An et al. 1999; Yu and Leibo 2002; Hishinuma et al. 2003) or cutting (Kishikawa et al. 1999) of epididymal tissue while allowing the sperm to swim up to a buffered medium for a few minutes is preferred in small animals. This technique can also be used in large animals (Hishinuma et al. 2003). Another possibility is the retrograde flushing of sperm from the tail of the epididymis using a needle connected to a syringe, 
containing either a flushing medium (Garde et al. 1998; Herold et al. 2004) or the air (Kikuchi et al. 1998; Ikeda et al. 2002).

Morphology evaluation has been one of the major parts of semen analysis for several decades. One of the first scientists to characterize and classify abnormal forms of sperm was Lagerlöf (1936), later followed by Bretschneider and Vaniterson (1948), Bonadona (1956) and many others. The development of a strict sperm morphology assessment (Kruger et al. 1986; Menkveld and Kruger 1995) was another step leading to more accurate sperm classification. Sperm morphology in some species, such as sheep and mice, is almost invariable, whilst morphology of bull (Gravance et al. 1996) and dog sperm (Dahlbom et al. 1997) differs between individual animals. Likewise, wild animal species exhibit significant differences in sperm morphology.

The knowledge of the maximum acceptable percentage of sperm with morphological anomalies is used in the production of insemination doses. In practice, certain cut-off values for sperm morphology have been set up over time for both farm and domestic animals. For example, in bulls, due to the association between the number of pathological forms of bovine sperm in the ejaculate and their fertilizing ability, the discriminating threshold value of $20 \%$ sperm with abnormal morphology was established. When exceeded, the ejaculate is not suitable for processing into insemination doses. Such thresholds have not yet been established for wild species of Bovidae, although some authors have already dealt with antelope semen characteristics (Cassinello et al. 1998; Sontakke et al. 2009).

Today, the Bovidae family comprises two subfamilies, Bovinae and Antilopinae (Robinson and Ropiquet 2011). According to the current taxonomy, all species of the Bovidae family are divided into 12 taxonomic units (tribus, tribes) (Groves and Grubb 2011). The Bovinae include Bovini, Tragelaphini, and Boselaphini; Antilopinae include Hippotragini, Alcelaphini, Antilopini, Aepycerotini, Caprini, Reduncini, Cephalophini, Neotragini and Oreotragini. The present study follows this classification of the species.

The aim of this study was to determine the prevalence of morphological defects of epididymal sperm in animals of the family Bovidae in species that are not native to the Czech Republic and are bred here only in zoos.

\section{Materials and Methods}

In the present study, testes and epididymides of wild species of the Bovidae family were used. The majority of organs were provided by the Dvi̊r Králové nad Labem ZOO and several Taurotragus oryx originated from the University Farm Estate Lány of the Czech University of Life Sciences Prague. The sampling was conducted for 11 years from 2007 to 2018, regardless of the season. The samples were taken after animals' death and were then transported to the laboratory on ice in a cooling box within $24 \mathrm{~h}$. The animals were either found dead or were slaughtered. The tail of the epididymis was gently dissected free from the reproductive organs. Great emphasis was put on avoiding contamination of the samples with blood. Latex-free gloves were used during the work. Samples were processed immediately upon receipt in the laboratory. The samples were moistened with phosphate-buffered saline at $4-8{ }^{\circ} \mathrm{C}$ to prevent the tissues from drying out. After processing, the tail of the epididymis was cut into small pieces. Where the veins could not be removed completely, the tail of the epididymis was cut in a vessel-free area. An appropriate amount of phosphate-buffered saline (pH 6.8) was added to immerse the prepared tissue. The supernatant was collected after $10 \mathrm{~min}$ using a Pasteur pipette. A smear was made, fixed with $3.5 \%$ formalin and stained with $5 \%$ aniline blue after $15 \mathrm{~s}$ and with $0.5 \%$ crystal violet after further 15 s (Aniline blue CI 427805; Crystal violet CI 42555; Sigma-Aldrich, St. Louis, USA). Morphological sperm defects were evaluated under a Nikon ECLIPSE 50i light microscope (Nikon Corporation Instruments Company, Yokohama, J) with $\times 1000$ magnification using immersion oil (Sigma-Aldrich, St. Louis, USA).

Multiparametric analysis was performed using the DeSMA software (Detailed Sperm Morphology Analysis, https://www.vri.cz/en/research/applying_results/software). All abnormalities were recorded for 200 spermatozoa in every smear. A total of 134 samples of sperm from animals classified in 32 species and 8 tribes were evaluated in this study. Ten species were represented by only one animal each. These were not included in the betweenspecies comparison of parameters, but they were included in the statistical comparison of tribes. The method of analysis of variance (ANOVA) using the SPSS software package, v.18 for Windows (SPSS, Inc., Chicago, USA) was used for testing the agreement of the means. A significance level of 0.05 was chosen for the testing of differences. 


\section{Results}

The average number of abnormal sperm in our group of animals of the Bovidae family was $51.2 \%$ (SD 20.3). Acquired defects overnumbered the developmental defects. The percentage of sperm showing at least one acquired defect was 38.9\% (SD 17.5), while the percentage of sperm showing developmental defects was $17.8 \%$ (SD 13.9). The teratogenic index reflected the number of defects per abnormal sperm at a value of 1.2 (SD 0.1). The following sperm defects were the most common: acquired head defects in 19.9\% (SD 17.6), mainly represented by acrosome defects in $10.1 \%$ (SD 10.4), and free heads in $6.8 \%$ (SD 11.8). The acquired abnormalities included tail defects in $14.9 \%$ (SD 7.9) and defects of the sperm neck in $12.6 \%$ (SD 15.1), with the vast majority formed by proximal cytoplasmic droplets in $12.3 \%$ (SD 15.1).

Developmental defects were most often found on the sperm heads in $11.0 \%$ (SD 11.1), followed by the tail defects in 4.9\% (SD 11.1), neck defects in 3.4\% (SD 4.1) and, finally, a very small percentage of defects of the midpiece in $0.4 \%$ (SD 0.6). The most common abnormality was the distal cytoplasmic droplet found in 17.7\% (SD 18.1) which, however, is not considered as a defect. The average percentages of sperm defects in different species are shown in Table 1. The average percentages of defects in different tribes are shown in Table 2. Only defects with significant between-tribe differences are presented.

\section{Statistical comparison of morphological defects in different species}

The percentage of developmental defects of sperm heads in the Hippotragus equinus was significantly higher compared to Taurotragus oryx, Nanger dama ruficolis, Connochaetes taurinus taurinus, Kobus megaceros and Kobus leche kafuensis. The percentage of acquired defects of sperm heads in the Aepyceros melampus was significantly higher compared to Addax nasomaculatus, Hippotragus equinus, Taurotragus oryx, Hippotragus niger, Connochaetes taurinus taurinus, Kobus ellipsiprymnus defassa and Kobus leche kafuensis. This difference was even bigger in the percentage of defective acrosomes, in which the Aepyceros melampus again differed from Addax nasomaculatus, Hippotragus equinus, Taurotragus oryx, Hippotragus niger, Connochaetes taurinus taurinus, Kobus ellipsiprymnus defassa and Kobus leche kafuensis, but also from Damaliscus pygargus phillipsi, Tragelaphus imberbis, Tragelaphus angasii, Tragelaphus spekii, Kobus megaceros and Kobus ellipsiprymnus ellipsiprymnus. The highest percentages of sperm with proximal cytoplasmic droplets were found in Oryx dammah and Addax nasomaculatus compared to Taurotragus oryx, Hippotragus niger, and Connochaetes taurinus taurinus. In addition, this percentage in Oryx dammah was higher than in Nanger dama ruficolis, Kobus megaceros, and Aepyceros melampus. The highest percentage of acquired defects of the sperm tail was observed in Hippotragus niger and differed significantly from Taurotragus oryx. Furthermore, the difference in the teratogenic index was significantly higher in Aepyceros melampus and Hippotragus equinus compared to Connochaetes taurinus taurinus. Aepyceros melampus also exceeded Ammotragus lervia. No significant differences were observed between different species in the percentages of normal sperm, distal droplets, free heads, developmental defects of the tail, defects of the midpiece, total number of developmental defects and total number of acquired defects.

\section{Statistical evaluation of morphological defects in individual tribes}

The highest but non-significant average percentage of normal sperm was detected in the Caprini. However, the tribe Alcelaphini significantly exceeded the values in the Hippotragini. The highest percentage of developmental defects was found in the Hippotragini which significantly differed from the Antilopini, Caprini, Alcelaphini and Tragelaphini. Acquired head defects were the most common finding in the Aepycerotini and differed significantly from the Bovini, Hipotragini, Reducini, Caprini, Alcelaphini and 
Table 1. Morphological defects of epididymal sperm of individual species of the family Bovidae.

\begin{tabular}{|c|c|c|c|c|c|c|c|c|}
\hline \multirow[b]{2}{*}{ Tribe + species } & \multirow[b]{2}{*}{$\mathrm{N}$} & \multirow{2}{*}{$\begin{array}{c}\text { Normal } \\
\text { spermatozoa } \\
(\%)\end{array}$} & \multicolumn{3}{|c|}{ Head abnormalities (\%) } & \multicolumn{3}{|c|}{ Neck abnormalities (\%) } \\
\hline & & & Primary & Acrosome & Loose heads & Primary & Secondary* & $\begin{array}{c}\text { Proximal } \\
\text { droplet }\end{array}$ \\
\hline \multicolumn{9}{|l|}{ Aepycerotini } \\
\hline Aepyceros melampus & 6 & $39.3(21.4)$ & $8.7(4.1)$ & $32.6(27.5)$ & $15.6(25.5)$ & $2.8(2.1)$ & $0.3(0.6)$ & $6.6(6.9)$ \\
\hline \multicolumn{9}{|l|}{ Alcelaphini } \\
\hline Damaliscus p. phillipsi & 4 & $62.0(19.2)$ & $6.4(4.5)$ & $5.9(4.5)$ & $2.6(1.1)$ & $0.5(0.4)$ & $0.1(0.3)$ & $13.9(20.4)$ \\
\hline Connochaetes gnou & 5 & $50.5(20.4)$ & $11.5(3.2)$ & $12.2(9.4)$ & $3.4(1.7)$ & $4.3(2.1)$ & $0.6(0.7)$ & $9.1(13.6)$ \\
\hline Connochaetes t. albojubatus & 1 & 52.5 & 10.5 & 6.0 & 1.5 & 2.0 & 0.0 & 1.5 \\
\hline Connochaetes t. taurinus & 6 & $65.2(9.9)$ & $5.7(5.0)$ & $6.3(3.4)$ & $1.9(2.6)$ & $4.2(2.9)$ & $0.2(0.4)$ & $4.8(8.8)$ \\
\hline \multicolumn{9}{|l|}{ Antilopini } \\
\hline Antidorcas marsupialis & 2 & $50.8(17.3)$ & $1.3(1.8)$ & $10.8(6.0)$ & $11.3(13.1)$ & $0.8(0.4)$ & $0.3(0.4)$ & $7.8(11.0)$ \\
\hline Gazella leptoceros & 1 & 49.5 & 3.0 & 2.0 & 14.0 & 3.0 & 0.5 & 2.0 \\
\hline Madoqua kirkii & 1 & 54.0 & 21.5 & 5.5 & 2.0 & 3.5 & 0.5 & 6.5 \\
\hline Nanger dama ruficolis & 5 & $46.8(12.7)$ & $4.9(5.5)$ & $12.7(11.1)$ & $14.4(12.0)$ & $3.3(2.1)$ & $0.6(0.8)$ & $7.7(11.0)$ \\
\hline \multicolumn{9}{|l|}{ Bovini } \\
\hline Bos indicus & 1 & 39.0 & 8.5 & 17.0 & 5.5 & 2.5 & 0.0 & 16.0 \\
\hline Bos taurus (Dahome) & 1 & 64.0 & 2.5 & 6.5 & 1.0 & 0.5 & 0.0 & 2.0 \\
\hline Syncerus c. caffer & 2 & $33.8(13.1)$ & $10.8(5.3)$ & $6.8(1.1)$ & $4.8(3.2)$ & $2.3(1.1)$ & $0.0(0.0)$ & $23.8(33.6)$ \\
\hline Taurotragus oryx & 18 & $62.4(17.5)$ & $4.6(3.6)$ & $8.6(5.3)$ & $6.8(6.5)$ & $3.0(2.0)$ & $0.3(0.5)$ & $7.1(10.8)$ \\
\hline \multicolumn{9}{|l|}{ Caprini } \\
\hline Ammotragus lervia & 2 & $65.0(9.2)$ & $3.3(1.1)$ & $7.8(4.6)$ & $1.5(0.0)$ & $2.0(1.4)$ & $0.0(0.0)$ & $1.0(0.0)$ \\
\hline Capra hircus & 1 & 81.5 & 1.5 & 9.5 & 1.5 & 2.5 & 0.0 & 0.0 \\
\hline Ovibos moschatus & 1 & 46.0 & 16.0 & 5.5 & 1.5 & 7.5 & 0.5 & 10.0 \\
\hline Ovis aries & 2 & $68.5(12.0)$ & $3.3(2.5)$ & $19.0(10.6)$ & $2.5(0.7)$ & $2.5(1.4)$ & $0.3(0.4)$ & $0.8(0.4)$ \\
\hline \multicolumn{9}{|l|}{ Hippotragini } \\
\hline Addax nasomaculatus & 6 & $36.6(14.0)$ & $16.6(5.8)$ & $6.8(5.4)$ & $4.8(2.3)$ & $1.9(2.6)$ & $0.6(1.2)$ & $35.0(15.4)$ \\
\hline Hippotragus equinus & 6 & $35.3(22.3)$ & $29.8(18.9)$ & $6.0(4.0)$ & $2.7(3.0)$ & $3.6(3.3)$ & $0.1(0.2)$ & $22.1(23.9)$ \\
\hline Hippotragus niger & 10 & $43.8(16.4)$ & $17.4(17.3)$ & $9.8(8.8)$ & $5.5(4.3)$ & $2.6(2.0)$ & $0.4(0.4)$ & $5.1(4.9)$ \\
\hline Oryx dammah & 3 & $27.3(7.6)$ & $19.2(12.6)$ & $8.8(3.7)$ & $3.3(0.6)$ & $2.8(1.3)$ & $0.7(0.8)$ & $46.8(5.3)$ \\
\hline Oryx gazella & 1 & 63.5 & 6.5 & 22.0 & 0.5 & 1.0 & 0.0 & 1.5 \\
\hline Oryx leucoryx & 1 & 43.0 & 12.0 & 21.0 & 3.5 & 6.0 & 0.0 & 5.5 \\
\hline \multicolumn{9}{|l|}{ Reduncini } \\
\hline Kobus e. defassa & 8 & $37.7(15.6)$ & $19.6(7.7)$ & $3.9(1.5)$ & $4.3(3.6)$ & $5.7(5.2)$ & $0.3(0.7)$ & $19.7(10.2)$ \\
\hline Kobus e. ellipsiprymnus & 5 & $37.0(20.9)$ & $22.2(19.6)$ & $6.8(2.8)$ & $4.3(1.4)$ & $2.2(0.9) 0,2$ & $2(0.4)$ & $14.7(2.5)$ \\
\hline Kobus leche kafuensis & 7 & $57.3(22,5)$ & $7.4(5,6)$ & $7.8(5,8)$ & $2.0(1.5)$ & $2.5(2.6)$ & $0.2(0.4)$ & $12.4(20.5)$ \\
\hline Kobus megaceros & 10 & $48.4(30.0)$ & $10.4(14.0)$ & $9.2(4.6)$ & $12.3(26.9)$ & $6.1(12.2)$ & $0.2(0.2)$ & $9.0(13.3)$ \\
\hline Redunca fulvorufula & 1 & 55.5 & 17.5 & 6.5 & 0.5 & 10.5 & 0.0 & 5.0 \\
\hline \multicolumn{9}{|l|}{ Tragelaphini } \\
\hline Tragelaphus angasii & 3 & $55.3(23.0)$ & $5.8(3.2)$ & $5.7(4.9)$ & $5.5(3.3)$ & $1.2(0.8)$ & $0.0(0.0)$ & $15.2(16.5)$ \\
\hline Tragelaphus imberbis & 3 & $57.7(9.6)$ & $5.8(2.5)$ & $6.8(5.3)$ & $5.2(5.5)$ & $2.7(1.0)$ & $0.3(0.3)$ & $8.2(11.6)$ \\
\hline Tragelaphus spekii & 7 & $40.2(21.7)$ & $9.4(5.6)$ & $12.0(6.1)$ & $16.9(22.8)$ & $4.3(3.1)$ & $0.9(1.5)$ & $17.9(16.2)$ \\
\hline Tragelaphus strepsiceros & 4 & $34.3(18.7)$ & $6.3(3.5)$ & $23.8(25.3)$ & $15.8(10.4)$ & $5.1(2.0)$ & $0.8(0.9)$ & $14.4(17.8)$ \\
\hline
\end{tabular}




\begin{tabular}{|c|c|c|c|c|c|c|c|c|}
\hline \multirow[b]{2}{*}{ Tribe + species } & \multirow[b]{2}{*}{$\mathrm{N}$} & \multirow{2}{*}{$\begin{array}{l}\text { Distal } \\
\text { droplet } \\
(\%) \quad a b\end{array}$} & \multirow{2}{*}{$\begin{array}{c}\text { Primary } \\
\text { midpiece } \\
\text { abnormalities }(\%)\end{array}$} & \multicolumn{2}{|c|}{ Tail abnormalities (\%) } & \multirow{2}{*}{ Terato } & \multicolumn{2}{|c|}{ Total sperm abnormalities (\%) } \\
\hline & & & & Primary & Secondary $_{\mathrm{S}}$ & & X Primary & Secondary \\
\hline \multicolumn{9}{|l|}{$\overline{\text { Aepycerotini }}$} \\
\hline Aepyceros melampus & 6 & $32.3(22.3)$ & $0.4(0.4)$ & $3.0(1.1)$ & $14.2(6.4)$ & $1.4(0.2)$ & $13.3(4.3)$ & $52.8(24.7)$ \\
\hline \multicolumn{9}{|l|}{ Alcelapini } \\
\hline Damaliscus p. phillipsi & 4 & $29.1(28.6)$ & $0.3(0.3)$ & $4.3(2.3)$ & $12.8(4.2)$ & $1.2(0.1)$ & $11.0(6.5)$ & $30.9(18.0)$ \\
\hline Connochaetes gnou & 5 & $12.5(8.4)$ & $0.0(0.0)$ & $5.8(4.4)$ & $17.6(13.5)$ & $1.3(0.1)$ & $19.1(5.1)$ & $36.8(19.7)$ \\
\hline Connochaetes t. albojubatus & $s 1$ & 61.0 & 0.0 & 3.0 & 31.5 & 1.2 & 13.5 & 38.5 \\
\hline Connochaetes t. taurinus & 6 & $16.4(28.5)$ & $0.1(0.2)$ & $4.5(3.7)$ & $12.3(7.6)$ & $1.1(0.0)$ & $12.3(6.4)$ & $24.3(10.7)$ \\
\hline \multicolumn{9}{|l|}{ Antilopini } \\
\hline Antidorcas marsupialis & 2 & $2.8(1.8)$ & $0.0(0.0)$ & $5.3(7.4)$ & $17.5(7.1)$ & $1.1(0.0)$ & $7.3(8.8)$ & $43.0(9.2)$ \\
\hline Gazella leptoceros & 1 & 0.5 & 0.0 & 6.0 & 23.5 & 1.1 & 12.0 & 41.0 \\
\hline Madoqua kirkii & 1 & 9.5 & 0.0 & 0.5 & 16.5 & 1.2 & 23.5 & 28.5 \\
\hline Nanger dama ruficolis & 5 & $16.7(15.7)$ & $0.4(0.5)$ & $4.5(3.1)$ & $16.4(5.7)$ & $1.2(0.1)$ & $12.4(7.0)$ & $44.3(11.3)$ \\
\hline \multicolumn{9}{|l|}{ Bovini } \\
\hline Bos indicus & 1 & 13.0 & 0.0 & 7.0 & 20.5 & 1.3 & 17.0 & 49.0 \\
\hline Bos taurus (Dahome) & 1 & 38.5 & 0.0 & 1.0 & 26.0 & 1.1 & 4.0 & 33.5 \\
\hline Syncerus caffer caffer & 2 & $7.8(8.1)$ & $1.8(1.1)$ & $9.8(2.5)$ & $19.5(6.4)$ & $1.2(0.0)$ & $22.3(6.7)$ & $50.0(19.8)$ \\
\hline Taurotragus oryx & 18 & $26.1(15.7)$ & $0.2(0.3)$ & $5.9(6.2)$ & $8.8(4.0)$ & $1.2(0.1)$ & $12.8(9.1)$ & $27.6(12.1)$ \\
\hline \multicolumn{9}{|l|}{ Caprini } \\
\hline Ammotragus lervia & 2 & $3.3(4.6)$ & $0.0(0.0)$ & $0.0(0.0)$ & $21.5(7.8)$ & $1.1(0.0)$ & $5.0(2.8)$ & $30.8(11.7)$ \\
\hline Capra hircus & 1 & 17.0 & 0.0 & 0.0 & 7.0 & 1.2 & 4.0 & 16.5 \\
\hline Ovibos moschatus & 1 & 8.0 & 0.5 & 8.0 & 13.5 & 1.2 & 28.0 & 30.0 \\
\hline Ovis aries & 2 & $0.3(0.4)$ & $0.0(0.0)$ & $0.5(0.7)$ & $6.3(3.2)$ & $1.1(0.1)$ & $6.3(4.6)$ & $26.3(7.4)$ \\
\hline \multicolumn{9}{|l|}{ Hippotragini } \\
\hline Addax nasomaculatus & 6 & $23.2(12.9)$ & $0.3(0.3)$ & $5.9(3.7)$ & $10.9(6.1)$ & $1.3(0.1)$ & $22.9(8.4)$ & $51.4(16.6)$ \\
\hline Hippotragus equinus & 6 & $18.2(17.9)$ & $1.3(2.8)$ & $4.3(3.1)$ & $20.1(8.1)$ & $1.4(0.2)$ & $34.3(17.6)$ & $44.3(19.8)$ \\
\hline Hippotragus niger & 10 & $7.0(8.8)$ & $0.4(0.6)$ & $6.6(9.4)$ & $20.6(9.5)$ & $1.2(0.1)$ & $24.2(22.3)$ & $36.5(10.9)$ \\
\hline Oryx dammah & 3 & $13.8(14.0)$ & $0.3(0.3)$ & $5.5(2.6)$ & $9.7(3.3)$ & $1.3(0.2)$ & $24.2(12.6)$ & $61.0(7.4)$ \\
\hline Oryx gazella & 1 & 0.5 & 0.0 & 0.5 & 6.5 & 1.1 & 8.0 & 29.0 \\
\hline Oryx leucoryx & 1 & 8.5 & 1.0 & 6.0 & 18.0 & 1.3 & 24.0 & 41.5 \\
\hline \multicolumn{9}{|l|}{ Reduncini } \\
\hline Kobus e. defassa & 8 & $8.5(5.5)$ & $0.6(1.0)$ & $6.7(7.8)$ & $18.8(9.6)$ & $1.3(0.1)$ & $29.4(15.8)$ & $42.0(7.8)$ \\
\hline Kobus e. ellipsiprymnus & 5 & $16.6(20.8)$ & $0.6(0.7)$ & $8.3(12.8)$ & $20.0(8.0)$ & $1.3(0.0)$ & $30.2(21.9)$ & $41.9(6.7)$ \\
\hline Kobus leche kafuensis & 7 & $27.4(22.0)$ & $0.4(0.6)$ & $3.7(2.9)$ & $15.9(3.5)$ & $1.2(0.1)$ & $13.1(9.6)$ & $33.5(20.9)$ \\
\hline Kobus megaceros & 10 & $20.0(26.1)$ & $0.3(0.4)$ & $4.9(4.3)$ & $13.2(9.2)$ & $1.2(0.2)$ & $18.6(22.8)$ & $39.5(25.0)$ \\
\hline Redunca fulvorufula & 1 & 0.5 & 0.0 & 4.5 & 19.1 & 1.1 & 26.5 & 19.5 \\
\hline \multicolumn{9}{|l|}{ Tragelaphini } \\
\hline Tragelaphus angasii & 3 & $23.2(19.0)$ & $0.5(0.0)$ & $4.5(4.0)$ & $13.0(9.0)$ & $1.1(0.1)$ & $11.5(7.5)$ & $36.3(18.3)$ \\
\hline Tragelaphus imberbis & 3 & $11.3(13.6)$ & $0.0(0.0)$ & $3.7(1.4)$ & $17.7(3.7)$ & $1.2(0.1)$ & $11.5(1.8)$ & $34.3(11.8)$ \\
\hline Tragelaphus spekii & 7 & $18.2(17.0)$ & $1.3(0.7)$ & $2.7(1.9)$ & $13.7(5.3)$ & $1.3(0.1)$ & $15.6(6.2)$ & $51.7(20.9)$ \\
\hline Tragelaphus strepsiceros & 4 & $7.4(7.8)$ & $0.1(0.3)$ & $3.4(3.8)$ & $12.0(9.0)$ & $1.2(0.0)$ & $14.0(8.6)$ & $56.9(20.4)$ \\
\hline
\end{tabular}

Values are presented as means (standard deviation)

* Without proximal cytoplasmic droplet

Primary - developmental; Secondary - acquired 
Table 2. Selected morphological defects of tribes of the family Bovidae with a significant difference.

\begin{tabular}{|c|c|c|c|c|c|c|c|c|}
\hline \multirow[t]{2}{*}{ Tribe } & \multirow[t]{2}{*}{$\mathrm{N}$} & \multirow{2}{*}{$\begin{array}{c}\text { Normal } \\
\text { spermatozoa (\%) }\end{array}$} & \multicolumn{3}{|c|}{ Head abnormalities (\%) } & \multirow{2}{*}{$\begin{array}{c}\text { Secondary tail } \\
\text { abnormalities (\%) }\end{array}$} & \multicolumn{2}{|c|}{ Total sperm abnormalities (\%) } \\
\hline & & & Primary & Secondary & Acrosome & & Primary & Secondary \\
\hline \multirow[t]{2}{*}{ Aepycerotini } & 6 & $39.3(21.4)$ & $8.7(4.1)$ & $48.2(44.7)$ & $32.6(27.5)$ & $14.2(6.4)$ & $13.3(4.3)$ & $52.8(24.7)$ \\
\hline & & $14.0-64.0$ & $4.0-14.5$ & $15.5-125.0$ & $10.0-75.5$ & $6.5-22.5$ & $7.5-18.5$ & $27.5-83.5$ \\
\hline \multirow[t]{2}{*}{ Alcelaphini } & 16 & $59.0(16.2)$ & $8.0(4.8)$ & $10.5(7.0)$ & $8.0(6.3)$ & $15.3(9.8)$ & $14.2(6.4)$ & $30.7(15.5)$ \\
\hline & & $20.5-75.5$ & $0.5-16.0$ & $1.5-32.5$ & $1.5-28.0$ & $5.5-34.0$ & $5.5-24.0$ & $14.0-66.5$ \\
\hline \multirow[t]{2}{*}{ Antilopini } & 9 & $48.8(11.2)$ & $5.7(7.3)$ & $22.6(11.7)$ & $10.3(9.0)$ & $17.4(5.3)$ & $12.4(7.5)$ & $41.9(10.1)$ \\
\hline & & $27.0-63.0$ & $0.0-21.5$ & $7.5-43.5$ & $2.0-32.0$ & $8.0-24.0$ & $1.0-23.5$ & $26.5-56.5$ \\
\hline \multirow[t]{2}{*}{ Bovini } & 4 & $42.6(16.3)$ & $8.1(5.0)$ & $13.3(6.6)$ & $9.3(5.2)$ & $21.4(4.8)$ & $16.4(9.4)$ & $45.6(14.0)$ \\
\hline & & $24.5-64.0$ & $2.5-14.5$ & $7.5-22.5$ & $6.0-17.0$ & $15.0-26.0$ & $4.0-27.0$ & $33.5-64.0$ \\
\hline \multirow[t]{2}{*}{ Caprini } & 6 & $65.8(13.3)$ & $5.1(5.5)$ & $13.3(8.1)$ & $11.4(7.9)$ & $12.7(8.3)$ & $9.1(9.6)$ & $26.8(8.2)$ \\
\hline & & $46.0-81.5$ & $1.5-16.0$ & $6.0-28.5$ & $4.5-26.5$ & $4.0-27.0$ & $3.0-28.0$ & $16.5-39.0$ \\
\hline \multirow[t]{2}{*}{ Hippotragini } & 27 & $39.2(16.8)$ & $19.6(15.1)$ & $13.2(8.0)$ & $9.0(7.2)$ & $16.5(8.8)$ & $25.5(17.0)$ & $44.2(15.8)$ \\
\hline & & $4.5-63.5$ & $3.5-61.5$ & $2.5-36.5$ & $1.0-34.0$ & $2.5-33.5$ & $4.5-67.5$ & $11.0-76.0$ \\
\hline \multirow[t]{2}{*}{ Reduncini } & 31 & $46.0(23.5)$ & $14.2(12.8)$ & $13.2(15.1)$ & $7.0(4.4)$ & $16.5(8.1)$ & $22.3(18.6)$ & 38.5 (17.9) \\
\hline & & $1.0-84.0$ & $1.5-55.5$ & $1.5-89.0$ & $0.5-18.5$ & $1.5-34.0$ & $2.5-73.5$ & $12.0-93.0$ \\
\hline \multirow[t]{2}{*}{ Tragelaphini } & 35 & $53.7(20.7)$ & $5.9(4.2)$ & $20.2(18.9)$ & $10.6(10.3)$ & $11.2(5.9)$ & $13.3(7.7)$ & $37.1(18.8)$ \\
\hline & & $13.0-82.5$ & $1.0-17.5$ & $3.5-91.5$ & $1.5-61.5$ & $2.0-23.0$ & $3.0-31.0$ & $14.5-81.0$ \\
\hline
\end{tabular}

All values are presented as means (standard deviation).

Primary - developmental; Secondary - acquired

Tragelaphini. This phenomenon was mainly observed in acrosome defects, the percentage of which was significantly higher compared to all the other investigated tribes, while the differences in the number of free heads were non-significant. Out of the tail defects, significant differences were only found in the acquired defects, namely between the Bovini with the highest and the Tragelaphini with the lowest percentage of the defects. The highest overall prevalence of developmental sperm defects was detected in the Hipotragini and differed significantly from the Tragelaphini. The highest overall prevalence of acquired sperm defects was detected in the Aepycerotini and differed significantly from the Caprini.

\section{Discussion}

The prevalence of defects in the group of animals investigated in the present study was higher than in the domestic species of the Bovidae family. In breeding cattle, the expected prevalence of all sperm defects is up to $20 \%$ and the prevalence of developmental defects only up to $10 \%$ (Věžník et al. 2004). The number of the evaluated pathologies in our group averaged $51.2 \%$. There are no publications with a similar focus and scope for wildlife.

The values obtained in the animal species investigated in our study differed most considerably from those reported above for Hippotragus equinus in the number of developmental abnormalities on sperm heads, Hippotragus niger in the number of acquired tail abnormalities, Aepyceros melampus in the number of acquired head defects, mainly acrosome defects, and for both Addax nasomaculatus and Oryx dammah in the number of sperm with proximal cytoplasmic droplets.

In this study, six Hippotragus equinus were examined. One of them was 11 years old and showed testicular calcifications, one was 8 years old, two were 2 years old and two were under 2 years of age. All samples were examined within $24 \mathrm{~h}$ of sample collection. The majority of developmental pathologies of the sperm head were detected in the oldest animal 
with altered testicular structure and in the youngest animal, in which a high percentage of proximal droplets was found. These findings suggested that age and health condition might play an important role in the development of pathologies.

Ten Hippotragus niger were examined. Two of them were 6 years old, one was 3 years old and was found dead, two were 2 years old and the remaining animals were under 2 years of age. All samples were processed within $24 \mathrm{~h}$ of collection. Even though this group consisted of relatively young animals, an increased number of acquired tail defects was found in one older breeding male as well as in most of the young animals. This indicates that all of these animals could be biological relatives.

Six Aepyceros melampus were examined. One of them was a 10-year-old animal suffering from a phlegmon that had fathered the other animals; one was a 6-year-old animal affected by a disease, two animals were under 3 years of age and the remaining ones were under 2 years of age. Sperm from one animal was not examined within $24 \mathrm{~h}$. The worst results were detected in the diseased animal and also in the young animal, the sample of which was not processed soon enough. Due to the fact that this group was relatively small and Aepyceros melampus is the only species placed in the Aepycerotini tribe, the characteristics of the species were reflected in the characteristics of the entire tribe. The important factors here were the health condition, strong influence of biological relationship, and the time of sample processing.

Six Addax nasomaculatus were examined. Samples from all animals were processed within $24 \mathrm{~h}$. One animal was 9 years old, the rest were young animals under 2 years of age; two of them had epididymal cysts.

Three Oryx dammah were examined: one was 9 years old and two were under 2 years of age. We assumed that in these animals, especially in Addax nasomaculatus, the finding of the increased prevalence of proximal droplets was caused by the young age of the majority of animals in the examined group. This was confirmed by the obtained results in individual animals.

The results showed that the main factors distinguishing one species from another in the group of animals in the present study were the age of the animals, their health condition, and the biological relationship between the animals. Furthermore, time was a very important factor in the sample processing, however, in this group it manifested itself rather at the level of individual animals. Another factor was that epididymal sperm collection did not take place in a natural way as the samples were obtained after the death of the animals. In addition, samples were processed within $24 \mathrm{~h}$, whereas bull semen is processed immediately after collection. It is also important that the animals did not live under natural conditions and the samples were taken throughout the year, regardless of reproductive activity.

A characteristic feature of epididymal sperm in exotic species of the Bovidae family is the presence of cytoplasmic droplets. Both distal and proximal cytoplasmic droplets occurred at the same time in almost $30 \%$ of sperm. However, distal droplets are not considered as pathologies and thus, acquired head defects were the most common pathology.

The unique collection of animals of the Bovidae family used in this study was assembled over almost 10 years. In addition, a sperm bank was created when sample processing and subsequent examination were performed. Finally, it was possible to prepare insemination doses from 70 animals and, by virtue of this, 27 species have been preserved. In the future, the frozen epididymal sperm can be used for fertilization, thus contributing to the reproduction of these animals.

\section{Acnowledgements}

This work was supported by the Ministry of Education, Youth and Sports of the Czech Republic under the project CEITEC 2020 (LQ1601). 


\section{References}

An T, Wada S, Edashige K, Sakurai T, Kasai M 1999: Viable spermatozoa can be recovered from refrigerated mice up to 7 days after death. Cryobiology 38: 27-34

Bonadona T 1956: Di una particolare formazione alla testa dei nemaspermi bovini mesa in evidenze al microscopia elettronico (in Italian, A particular formation in the head of bovine normsperms evidenced by electron microscopy). Riv Biol 47: 297

Bretschneider LH, Vaniterson W 1948: Het electronenmicroscopisch Onderzoek van het Spermium van de Stier (in Dutch, Electron microscopy examination of bull sperm). Tijdschr Dierg 73: 233

Cassinello J, Abaigar T, Gomendio M, Roldan ER 1998: Characteristics of the semen of three endangered species of gazelles (Gazella dama mhorr, G. dorcas neglecta and G. cuvieri). J Reprod Fertil 113: 35-45

Dahlbom M, Anderson M, Vierula M, Alanko M 1997: Morphometry of normal and teratozoospermic canine sperm heads using an image analyzer: work in progress. Theriogenology 48: 687-698

Foote R 2000: Fertilizing ability of epididymal sperm from dead animals. J Androl 21: 355

Garde J, Ortiz N, Garcia A, Gallego L, Landete CT, Lopez A 1998: Post-mortem assessment of sperm characteristics of the red deer during the breeding season. Arch Androl 41: 195-202

Gravance CG, Visvanath R, Pitt C, Casey PJ 1996: Computer automated morphometric analysis of bull sperm heads. Theriogenology 46: 1205-1215

Groves C, Grubb P 2011: Ungulate Taxonomy. The Johns Hopkins University Press, Baltimore, 317 p.

Herold FC, Aurich JE, Gerber D 2004: Epididymal sperm from the African buffalo (Syncerus caffer) can be frozen successfully with AndroMed and with Triladyl but the addition of bovine seminal plasma is detrimental. Theriogenology 61: 715-724

Hishinuma M, Suzuki K, Sekina J 2003: Recovery and cryoconservation of sika deer (Cervus nippon) spermatozoa from epididymides stored at $4^{\circ} \mathrm{C}$. Theriogenology 59: 813-820

Ikeda H, Kikuchi K, Noguchi J, Takeda H, Shimada A, Mizokami T 2002: Effect of preincubation of cryopreserved porcine epididymal sperm. Theriogenology 57: 1309-1318

Kikuchi K, Nagai T, Kashiwazaki N, Ikeda H, Noguchi J, Shimada A 1998: Cryoconservation and ensuring in vitro fertilization ability of boar spermatozoa from epididymides stored at $4^{\circ} \mathrm{C}$. Theriogenology 50 : $615-623$

Kishikawa H, Tateno H, Yanagimachi R 1999: Fertility of mouse spermatozoa retrieved from cadavers and maintained at $4^{\circ} \mathrm{C}$. J Reprod Fertil 116: $217-222$

Kruger TF, Menkveld R, Stander FSH, Lombard CJ, Vandermerve JP, Vanzyl JA, Smith K 1986: Sperm morphologic features as a prognostic factor in vitro fertilization. Fertil Steril 46: 1118-1123

Lagerlöf N 1936: Sterility of bulls. Vet Rec 12: 121-129

Martinez-Pastor F, Garcia-Macias V, Alvarez M, Chamorro C, Herraez P, de Paz P, Anel L 2006: Comparison of two methods for obtaining spermatozoa from the cauda epididymis of Iberian red deer. Theriogenology $\mathbf{6 5}$ : 471-485

Menkveld R, Kruger TF 1995: Advantages of strict (Tygerberg) criteria for evaluation of sperm morphology. Int J Androl 2: 36-42

Robinson TJ, Ropiquet A 2011: Examination of hemiplasy, homoplasy and phylogenetic discordance in chromosomal evolution of the Bovidae. Syst Biol 60: 439-450

Roth TL, Weiss RB, Buff JL, Bush LM, Wildt DE, Bush M 1998: Heterologous in vitro fertilization and sperm capacitation in an endangered African antelope, the scimitar-horned oryx (Oryx dammah). Biol Reprod 58: $475-482$

Songsasen N, Tong J, Leibo S 1998: Birth of live mice derived by in vitro fertilization with spermatozoa retrieved up to twenty-four hours after death. J Exp Zool 280: 189-196

Sontakke SD, Patil MS, Umapathy G, Rao KR, Shivaji S 2009: Ejaculate characteristics, short-term storage and successful artificial insemination following synchronization of oestrus in the Indian blackbuck antelope (Antilope cervicapra). Reprod Fertil Dev 21: 749-756

Suwanpugdee A, Kornkeawrat K, Saikhun K, Siriaroonrat B, Tipkantha W, Dougsa-ard K, Sa-ardrit M, Suthunmapinatha P, Pinyopummin A 2009: Semen characteristics and sperm morphology of serow (Capricornis sumatraensis). Theriogenology 71: 576-585

Turner T 1995: On the epididymis and its role in the development of the fertile ejaculate. J Androl 16: 292-298

Věžník Z, Švecová D, Zajícová A, Přinosilová P 2004: Repetitorium spermatologie a andrologie a metodiky spermatoanalýzy (in Czech, Repetitorium of spermatology and andrology and methods of spermatoanalysis). Veterinary Research Institute, Brno, 197 p.

Wildt DE, Howard LG, Hall LL, Bush M 1986: Reproductive physiology of the clouded leopard. I. Ejaculates contain high proportion of pleiomorphic spermatozoa throughout the year. Biol Reprod 34: 937-947

Yu I, Leibo S 2002: Recovery of motile, membrane-intact spermatozoa from canine epididymides stored for 8 days at $4^{\circ} \mathrm{C}$. Theriogenology 57: 1179-1190 